NIST Technical Note 1892

\title{
Impact of Electricity Tariff Parameters on Net Zero Home Cost of Energy
}

\author{
Andrew Kuo \\ David G. Holmberg \\ Steven T. Bushby
}

This publication is available free of charge from:

http://dx.doi.org/10.6028/NIST.TN.1892 
NIST Technical Note 1892

\title{
Impact of Electricity Tariff Parameters on Net Zero Home Cost of Energy
}

\author{
Andrew Kuo \\ Dakota Consulting \\ Silver Spring, MD \\ David G. Holmberg \\ Steven T. Bushby \\ Energy and Environment Division \\ Engineering Laboratory
}

This publication is available free of charge from:

http://dx.doi.org/10.6028/NIST.TN.1892

September 2015

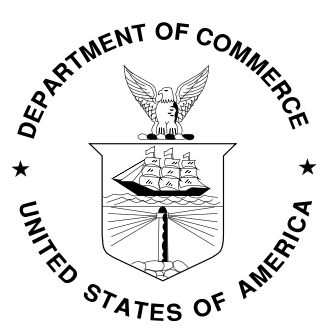

U.S. Department of Commerce

Penny Pritzker, Secretary

National Institute of Standards and Technology

Willie May, Under Secretary of Commerce for Standards and Technology and Director 


\section{Disclaimer}

Certain commercial entities, equipment, or materials may be identified in this document in order to describe an experimental procedure or concept adequately. Such identification is not intended to imply recommendation or endorsement by the National Institute of Standards and Technology, nor is it intended to imply that the entities, materials, or equipment are necessarily the best available for the purpose.

National Institute of Standards and Technology Technical Note 1892 Natl. Inst. Stand. Technol. Tech. Note 1892, 22 pages (September 2015) CODEN: NTNOEF

This publication is available free of charge from: http://dx.doi.org/10.6028/NIST.TN.1892 


\section{ABSTRACT}

Time-varying electricity rates impact the costs of operation and the value of renewable generation and storage resources. This study investigates the economic impact of electricity tariff parameters on the value of solar photovoltaic (PV) systems in the National Institute of Standards and Technology's Net-Zero Energy Residential Test Facility (NZERTF) and the potential benefits of adding batteries for electrical storage. The NZERTF is a highly energy-efficient house designed to generate as much electrical energy from the PV array as the house consumes in a year.

The Hybrid Optimization Model for Electric Renewables (HOMER) was used to determine the homeowner's cost of energy (COE) for three different electricity tariff types (flat rate, time-ofuse, and real-time-pricing) and three independent variables (energy storage size, energy sellback rate, and demand charges). The analysis was based on the installed cost of the PV system, measured house electricity consumption, commercially available battery storage system cost data, and published electricity tariffs with cost corrections for the sellback rate and demand charges. The batteries are used to store energy from the PV array or the grid when prices are low and discharge energy when prices are high. This work does not consider the value of batteries to serve various other use cases (e.g., back-up power or voltage regulation). There is no simulation of energy management (load shifting or shedding) in the house.

Results show that for three of the four tariffs the addition of PV and batteries increased COE. The exception was a tariff with the highest prices and most significant difference between peak and off-peak prices. When Maryland renewable energy credits were accounted for, the use of PV became economically viable for all tariffs; however, adding batteries was still not justified (based on arbitrage alone) for three of the four tariffs. The COE with and without batteries was not influenced by demand charges; this was attributed to a HOMER battery charging algorithm which accounted for real-time energy prices but did not account for demand charges. Finally, results showed that the amount of power from the PV system that was actually consumed directly by loads in the house was $58 \%$.

Keywords: cost of energy, distributed energy resources, demand charge, electricity tariff, HOMER, net-zero energy, renewable fraction, residential, sellback rate, solar photovoltaics

\section{Acknowledgment}

The work presented here was supported by the NZERTF researchers at National Institute of Standards and Technology. Thanks to Brian Dougherty, Joshua Kneifel, Farhad Omar, and Mark Davis for providing essential NZERTF energy consumption data and PV performance data. 


\section{Contents}

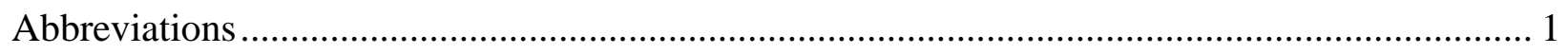

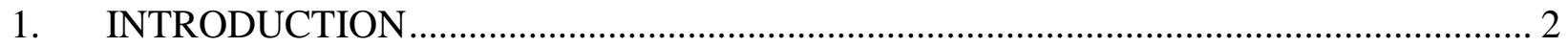

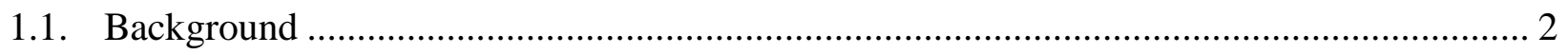

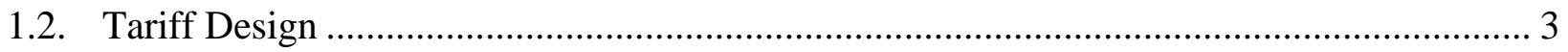

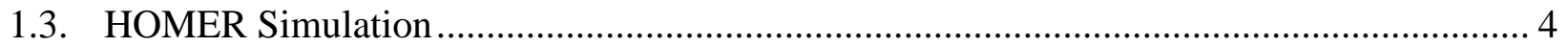

1.4. Net Zero Energy Residential Test Facility ........................................................................... 4

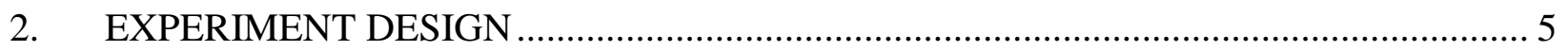

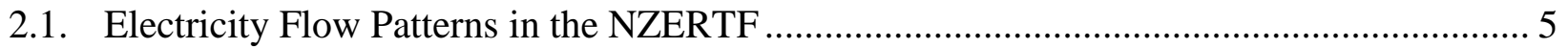

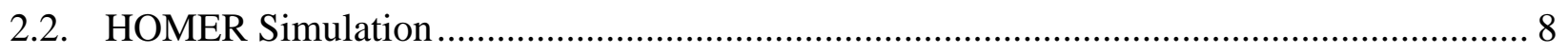

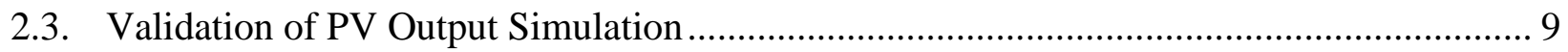

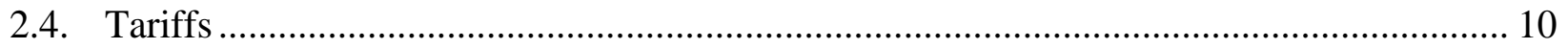

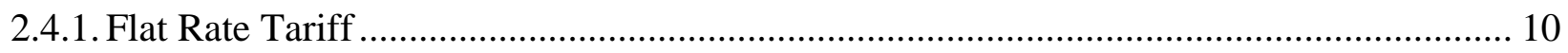

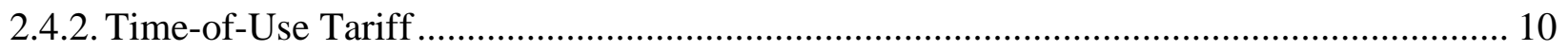

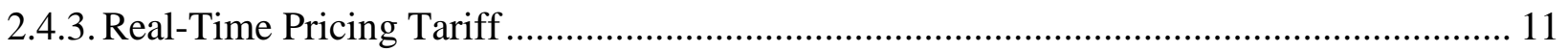

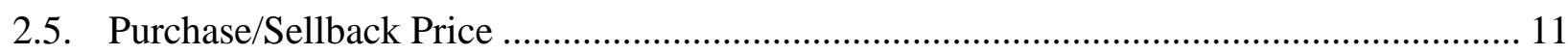

2.6. Demand Charge …………………………......................................................... 12

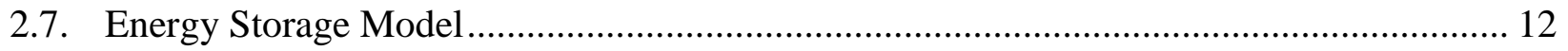

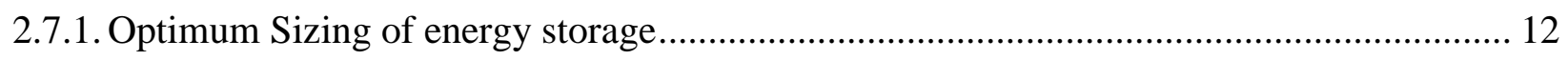

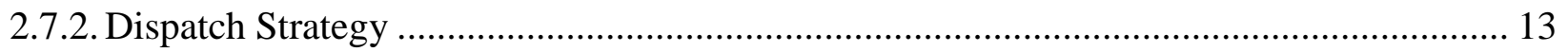

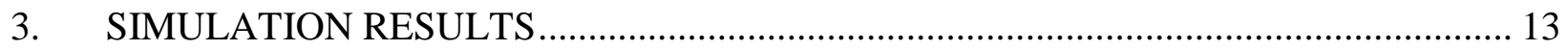

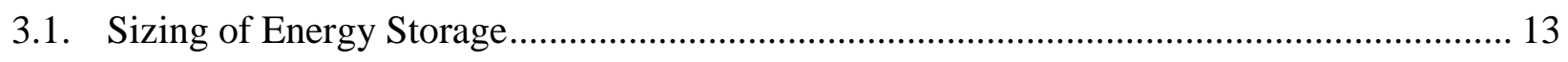

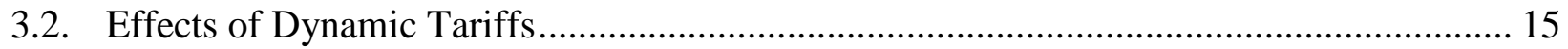

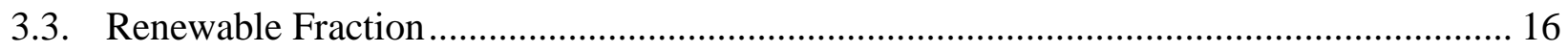

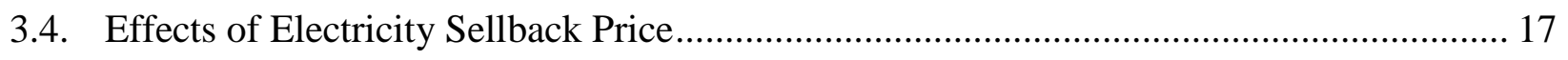

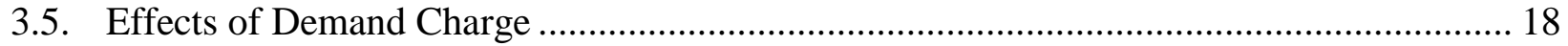

3.6. Impacts of tax credits on COE in Maryland ..................................................................... 19

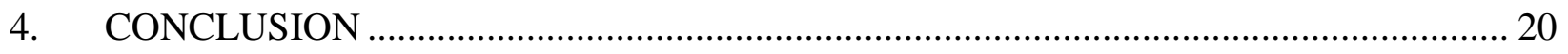

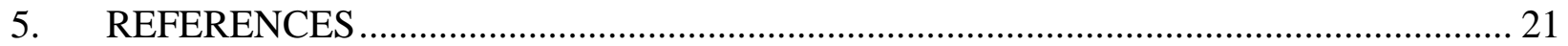



Abbreviations
- COE cost of energy
- ComEd Commonwealth Edison (Chicago)
- ConEd Consolidated Edison (New York)
- DLC direct load control
- DR demand response
- DOE Department of Energy
- DER distributed energy resource
- HOMER Hybrid Optimization Model for Electric Renewables
- NASA National Aeronautics and Space Administration
- NIST National Institute of Standards and Technology
- NOAA National Oceanic and Atmospheric Administration
- $\quad$ NZERTF Net-Zero Energy Residential Test Facility
- OG+E Oklahoma Gas and Electric
- PEPCO Potomac Electric Power Company
- PJM PJM Interconnection LLC, a regional transmission organization
- PV photovoltaic
- RRTP residential real-time pricing
- TOU time-of-use
- TMY typical meteorological year 


\section{INTRODUCTION}

\subsection{Background}

The U.S. electric grid utilization rate is low, with on average only $47 \%$ of U.S. generation capacity being used on an annual basis [1]. In the northeast U.S., $20 \%$ of the generation capacity is used only $3 \%$ of the time to manage peak loads [2]. These peaks typically occur in the summer on hot afternoons when air conditioning loads peak, while some utilities in colder climates experience peak loads for heating on winter mornings.

In addition to a low-utilization rate for grid generation capacity, the generation mix itself is changing with the growing amount of intermittent wind and solar photovoltaic (PV) generation. Intermittent generation requires responsive load or storage to use generated power at the time the wind is blowing or sun is shining.

The results of many utility pilots [3] have shown that residential, commercial, and industrial customers will respond to varying electricity prices by reducing load when prices are high and shifting load to low-price periods. Therefore, varying electricity prices can help utilities manage the low generation capacity utilization problem as well as motivate customers to shift load to follow generation.

For these reasons and more, there is a gradual move toward tariffs that have dynamic prices that more closely reflect actual wholesale market electricity prices, all day and every day of the year. Customers pay higher prices on-peak and lower prices off-peak. This encourages customers to manage energy use to save money and incentivizes customers to invest in automation and storage technologies.

The goal of this present work is to examine the impact of several existing dynamic tariffs on the value of PV systems in the National Institute of Standards and Technology's Net-Zero Energy Residential Test Facility (NZERTF) and the potential benefits of adding batteries for electrical storage. The NZERTF is a highly energy-efficient house designed to generate as much electrical energy from the PV array as the house consumes over an entire year.

The NZERTF serves as a use case for a highly energy-efficient modern house (the NZERTF uses $40 \%$ of the energy of a typical energy code-compliant home [4]) ready to participate in a smart grid environment. The current research asks how much impact different tariff structures would have on the electric bill assuming the occupant comfort and load use schedule are not adjusted.

While some published research examines the impact of different forms of demand response programs and tariffs in eliciting customer response, e.g., [3], this report is not looking at customer response to dynamic tariffs. Rather it takes the consumption data from the NZERTF and examines the impact of several tariff parameters on the electric bill to evaluate the costeffectiveness of PV and battery systems. 


\subsection{Tariff Design}

Tariff design is a complicated process in the U.S., involving over 3,000 utilities, 50 state regulatory bodies, and consumer advocates. Figure 1 shows four example tariffs. In a flat rate tariff the cost of electricity is constant. A time-of-use (TOU) tariff has prices that vary based on a set schedule that may have seasonal variations. There may be very large price differences that encourage customers to invest in automation for load management as well as storage technology to allow shifting energy use from peak periods to off-peak periods.

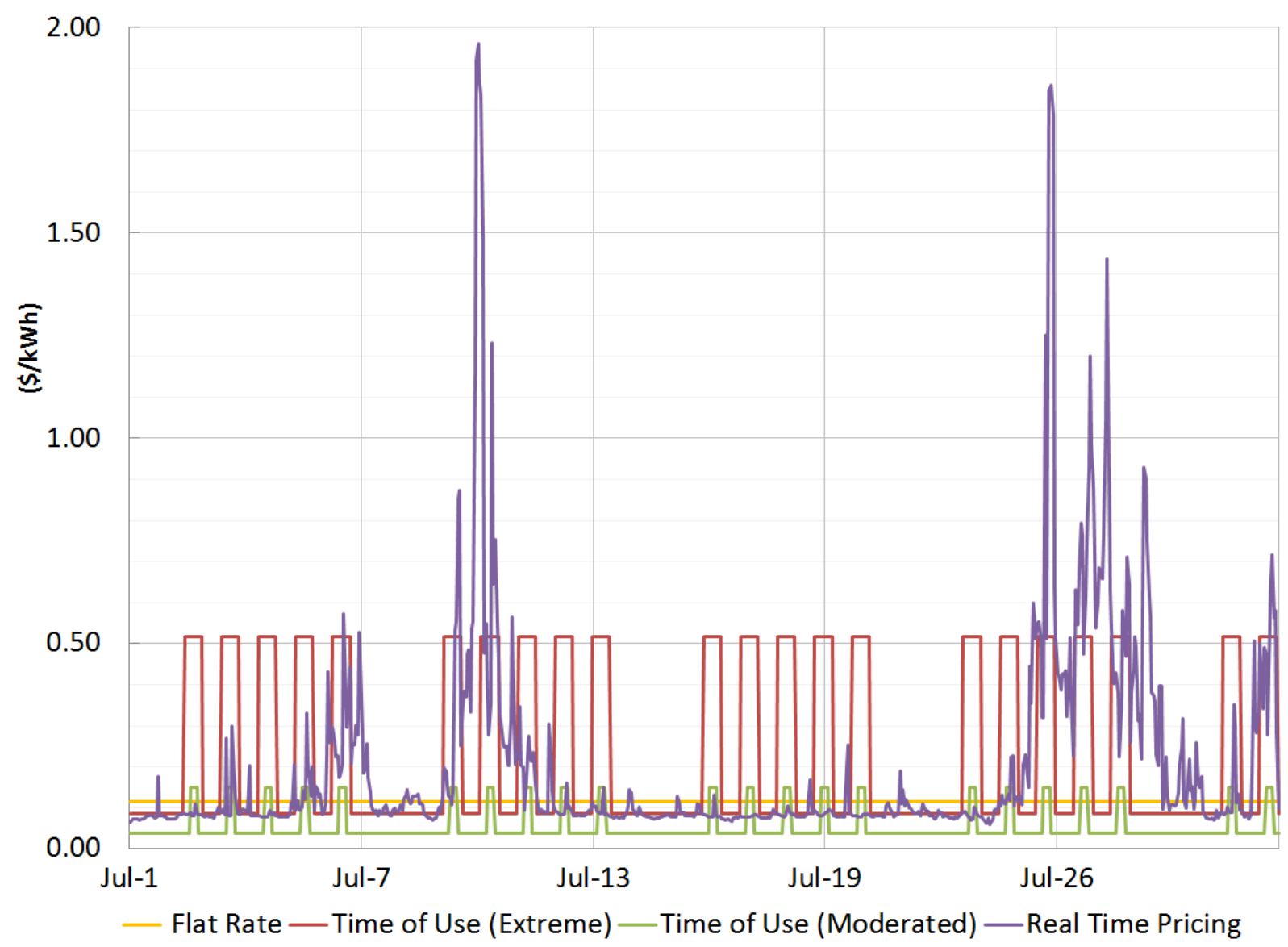

Figure 1. Example tariffs: flat rate, time-of-use, and real-time pricing.

TOU tariffs do not require active communication of prices on a day-to-day and hour-by-hour basis since the schedule is published within the tariff. However, a TOU tariff does not provide a signal that would allow customer loads to respond to real-time variation of grid supply and transmission congestion due to weather, outage, or other variability. Normally, TOU prices are higher in the afternoon from 2 p.m. to 5 p.m., lower at night from 10 p.m. to 10 a.m. and higher during the week than weekends. The TOU rate reflects average generation costs during those time periods.

Some dynamic tariffs have been implemented that track real-time wholesale market prices more closely. The customer pays for electricity based on the real-time or day-ahead market prices or 
some function of these prices. One possible benefit of a real-time price is that it enables a customer to manage loads in a way that is more responsive to real-time supply and transmission constraints.

Some utility tariffs include a demand charge. The customer pays for monthly energy use (kWh) as well as a portion based on peak power consumption $(\mathrm{kW})$. If a customer can manage loads or utilize batteries to reduce peak demand, then they can reduce the monthly demand charge portion of their electric bill.

Many tariffs provide some form of net-metering for residential customers with PV generation. This provides payment for conditions when the PV panels produce more power than is consumed at that instant in the home, during which the power flows out through the meter to the grid. However, the "sellback rate" varies among utilities and in different states.

\subsection{HOMER Simulation}

The intermittent and non-dispatchable nature of renewable power sources like PV increases the complexity of power output estimation. The simulation software "Hybrid Optimization Model for Electric Renewables" (HOMER) [5] was used to conduct the analysis in this report. HOMER models the hourly performance of a renewable energy microgrid system configuration and calculates life-cycle cost. It enables parametric testing of system configuration details and tariffs.

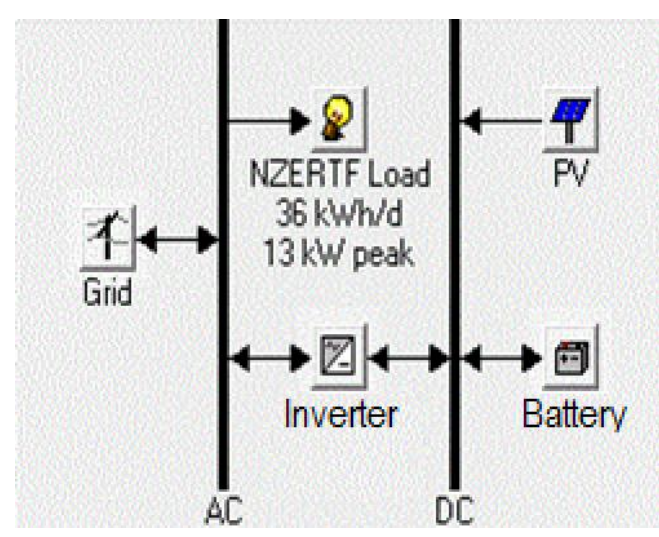

Figure 2. HOMER simulation model.

Figure 2 shows the HOMER simulation design scheme for the NZERTF with additional battery storage. The model includes the hourly energy consumption for a one year period, various electricity pricing options, a PV panel that produces hourly simulated solar output based on designated location, an inverter for AC/DC and DC/AC power conversion, and a battery for energy storage. More details of the model are given later in this paper.

\subsection{Net Zero Energy Residential Test Facility}

The NZERTF, at the National Institute of Standards and Technology (NIST) in Gaithersburg, Maryland, is a single family residence built in a style and size that would be typical for singlefamily homes in the Washington DC area. A photo of the home is shown in Figure 3. The NZERTF is designed to operate as a net-zero energy home, with a simulated family of four living virtually in the house. The simulated occupants use the stove, take showers, watch TV, and perform other normal family activities. The virtual family's energy consumption pattern is programmed according to published behavior surveys of an American family lifestyle [6]. 
This home has a smart meter that accounts separately for electricity flow into and out of the house. In addition, a separate meter records PV generation, and each circuit in the house is independently metered. The NZERTF was operated continuously for a one year period (July 2013 - June 2014) to demonstrate net zero energy capability [7]. Electrical energy production and consumption measurements taken during this test were used in the HOMER simulations.

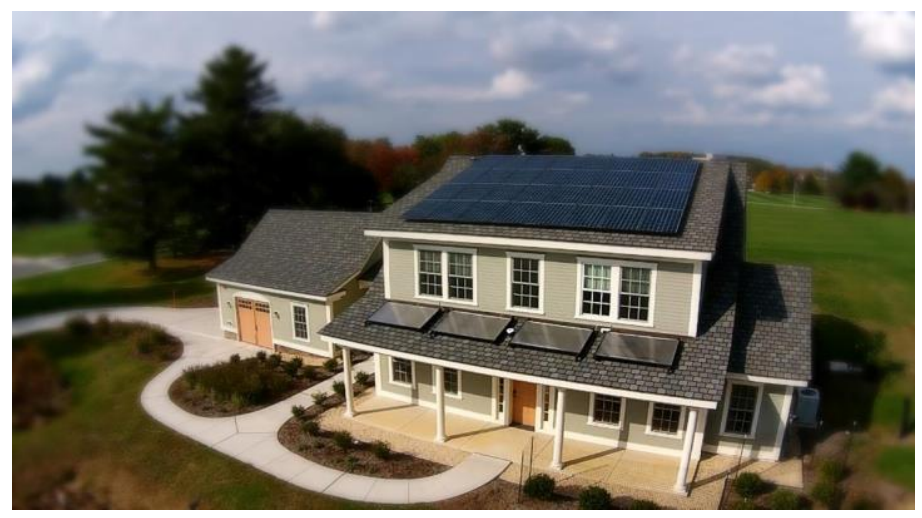

Figure 3. NIST Net-Zero Energy Residential Test Facility (NZERTF).

\section{EXPERIMENT DESIGN}

\subsection{Electricity Flow Patterns in the NZERTF}

Experimental measurements of electricity flows during the one-year net-zero energy test period for the NZERTF were used to characterize the load and to validate the PV output modeled using HOMER. Figure 4 shows schematically the flow of electricity during times when PV generation is available and when it is not. When PV generation is available, electricity flows to NZERTF loads and any excess generation capacity is fed into the grid. Any shortfall in capacity is made up with electricity from the grid. When no PV generation is available, such as at night, the grid supplies the entire load.

\section{PV is Available}

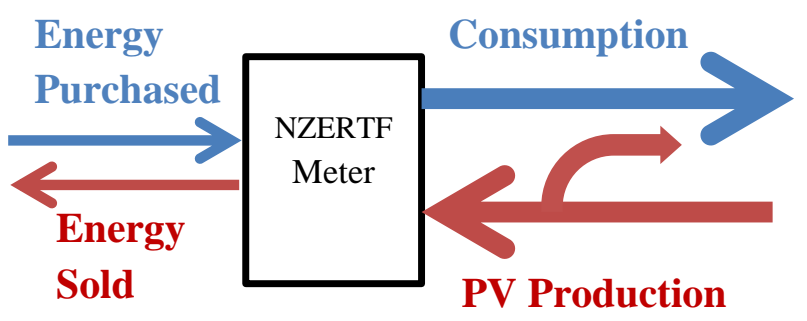

\section{PV is Not Available}

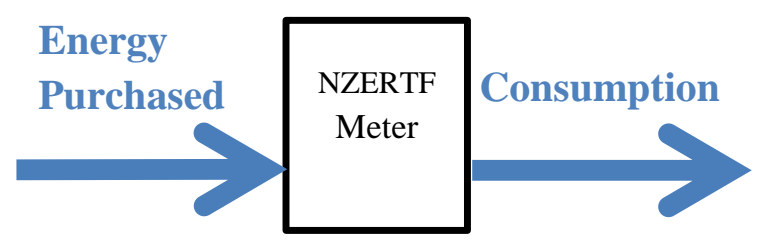

Figure 4. Electricity flow patterns when PV is and is not available.

The months of July and December 2013 were selected as representative months for electricity consumption and production for summer and winter respectively. Figure 5(a) and Figure 5(b) show the monthly average July and December daily NZERTF meter data. In Figure 5(a), there is only one-way electricity flow during the nighttime (9 p.m. to 5 a.m.) where purchased energy 
(purple dotted line) is equal to aggregated load consumption (blue line). Electricity flow becomes more complicated during the day (6 a.m. to 8 p.m.), when PV production plus purchased energy is equal to aggregated load consumption plus energy sold back to the grid. In Figures 5(a) and 5(b) there are times when the data indicates selling and purchasing energy at the same time. This is the result of averaging over the month. On some days at a particular time, energy was being bought and on others at the same time it was being sold. The weekly occupancy schedule for the virtual family is fixed. Seasonal variations in energy consumption are the result of changes in HVAC loads required to meet thermal comfort conditions.

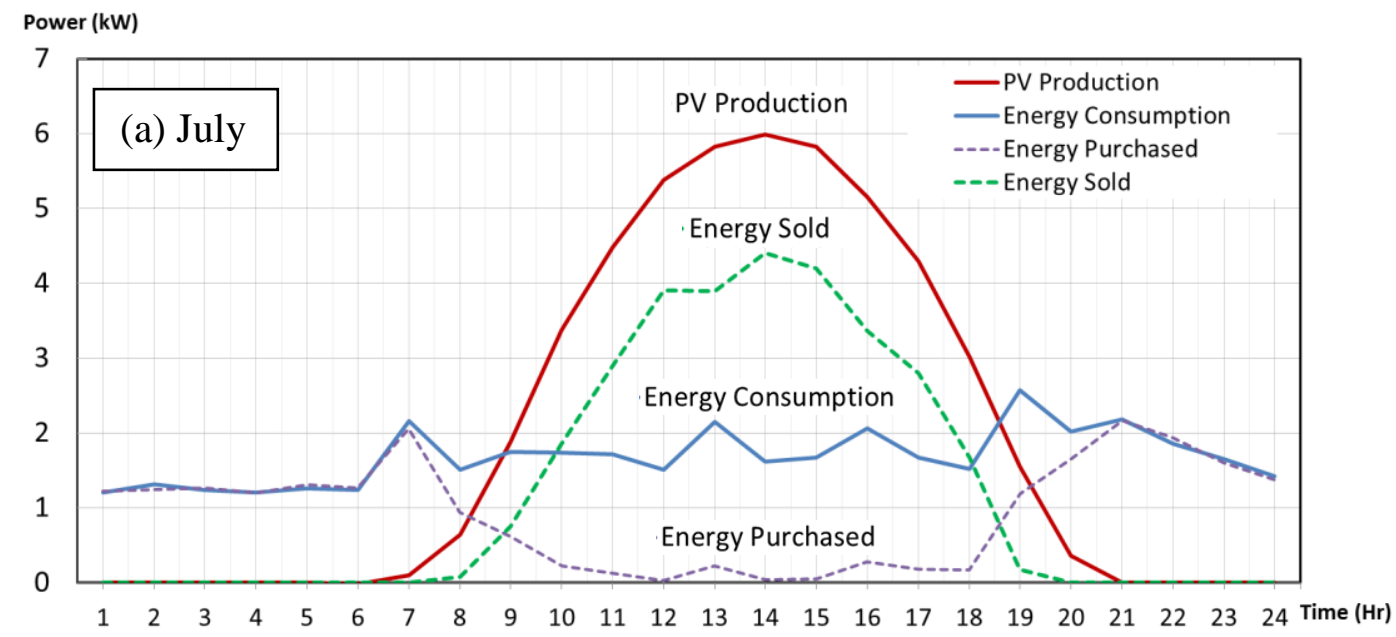

Figure 5(a). Monthly average NZERTF meter data for July 2013 indicating energy consumption, PV production, energy purchased, and energy sold.

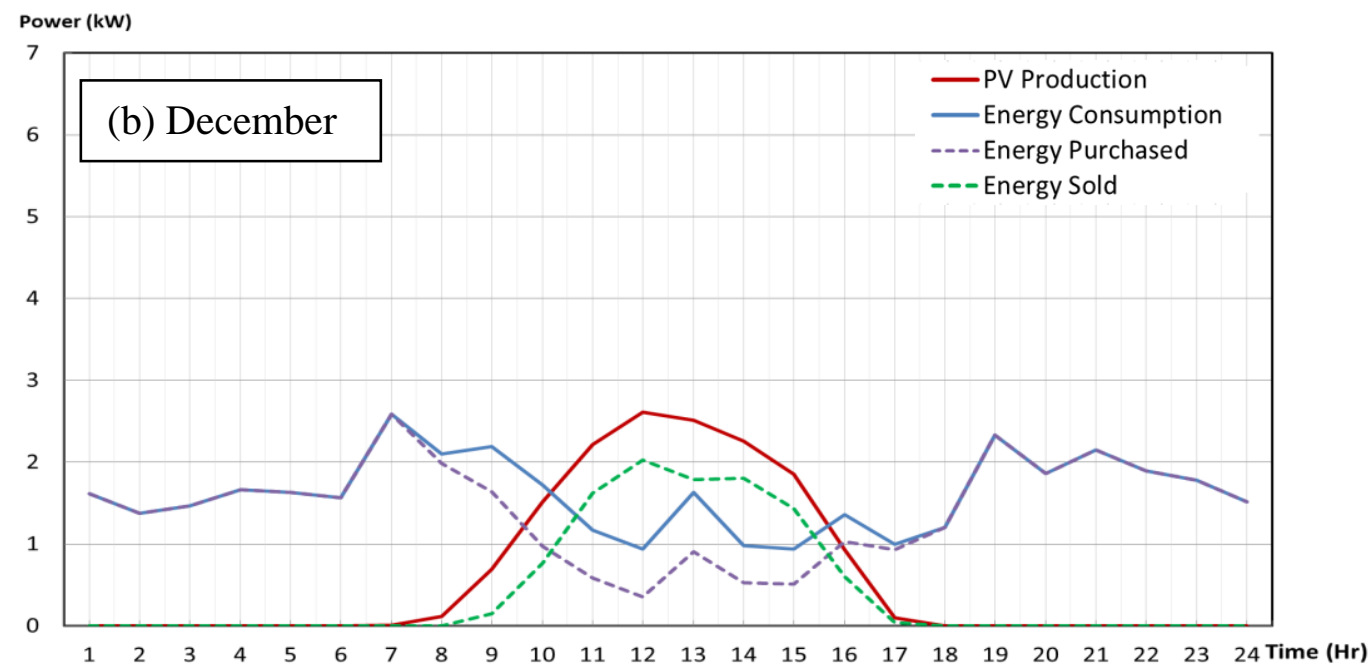

Figure 5(b). Monthly average NZERTF meter data for December 2013 indicating energy consumption, PV production, energy purchased, and energy sold. 
Figure 6 presents the hourly average meter data for July 1, 2, and 3, which illustrate the daily variation in PV production and HVAC load due to outdoor temperature and cloud cover. The periods of simultaneous buying and selling of energy are the result of PV output fluctuations during the hour.
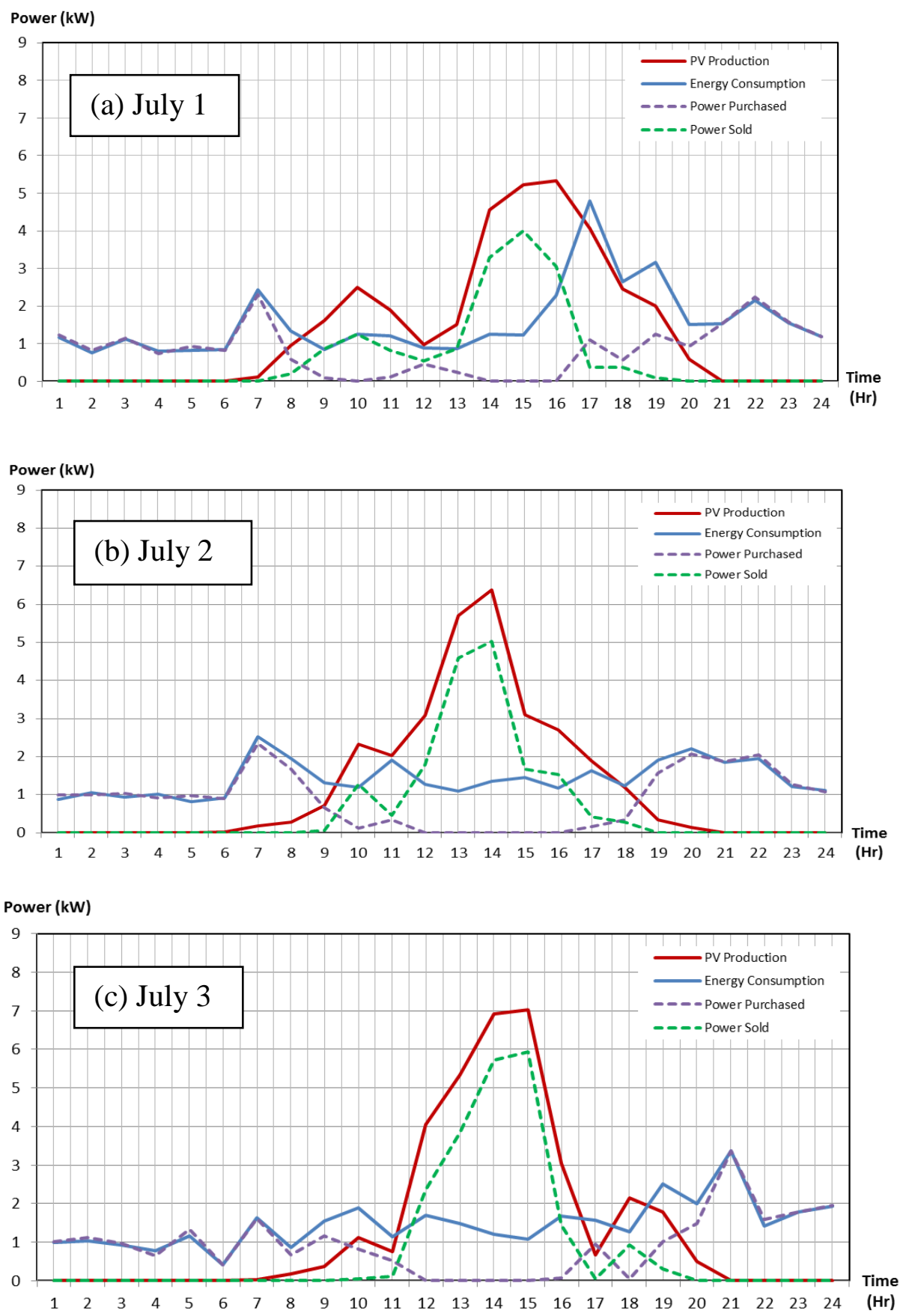

Figure 6. Hourly average NZERTF meter data in (a) July 1, 2013, (b) July 2, 2013, and (c) July 3, 2013. 


\subsection{HOMER Simulation}

The input parameters used for the HOMER simulations are shown in Figure 7. The control parameters were varied to explore the impact of various electricity costs and battery storage options. The measured load and actual size and characteristics of the NZERTF PV array were used. Historical average monthly insolation measurements (from July 1983 to June 2005) [8] were used to calculate PV output.

Installation costs, replacement costs, and operations and maintenance (O\&M) costs of NIST's net-zero energy residential test facility are also included in the HOMER simulation:

- $10.2 \mathrm{~kW}$ PV array: $\$ 28,608$ installation, $\$ 6,000$ replacement, $\$ 160 /$ year for O\&M;

- $10 \mathrm{~kW}$ inverter: $\$ 2,200$ installation, $\$ 2,000$ replacement, $\$ 50 /$ year for O\&M; and

- $9.8 \mathrm{kWh}$ battery storage module: $\$ 4,460$ installation, $\$ 800$ replacement, $\$ 0 /$ year O\&M.

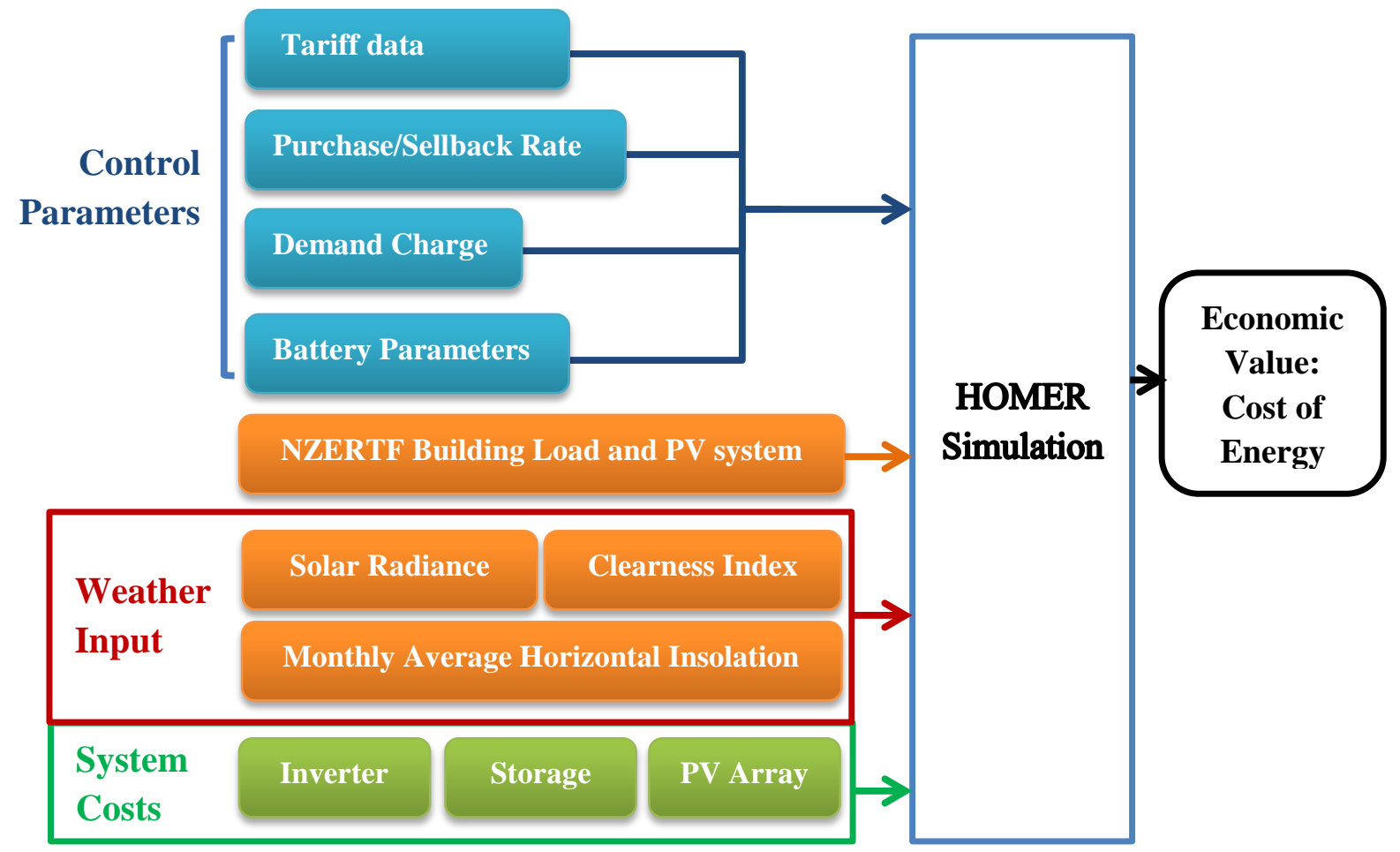

Figure 7. Simulation design diagram for evaluating customer distributed energy resources in NZERTF.

The HOMER simulation is based on the microgrid model shown in Figure 2. The weather data and PV system parameters are used to estimate PV generation. Electricity flows through the house meter and to/from the battery are calculated, and the appropriate costs or credits assigned based on the applicable tariff. The life cycle system costs for an assumed 25 year period are factored in to determine a normalized cost of energy (COE) defined in Equation 1 [5]. 


$$
C O E=C_{a n n, t o t} / E_{a n n, s e r v}
$$

where,

$$
\begin{aligned}
& C_{a n n, t o t}=\text { total annualized net present cost of system }(\$ / y e a r) \\
& E_{a n n, \text { serv }}=\text { total electrical load served }(\text { consumed }+ \text { sold to grid })(\mathrm{kWh} / \text { year })
\end{aligned}
$$

In order to understand the economic value of customer distributed energy resources, three configurations of the NZERTF are examined in this report:

- No Customer Distributed Energy Resource (No DER) - NZERTF residential load with the grid interconnection only (no PV system);

- PV - NZERTF Residential load connected with rooftop PV array, inverters, and the grid interconnection; and

- PV + Storage - NZERTF residential load connected with rooftop PV array, inverters, energy storage, and the grid interconnection.

\subsection{Validation of PV Output Simulation}

To validate HOMER's solar production relative to NZERTF measurements, the HOMER PV output was compared to NZERTF data. Figure 8 shows NZERTF PV production versus HOMER estimated solar energy, in kWh. Both results included inverter losses. The total annual NZERTF metered solar production ${ }^{[1]}(14,045 \mathrm{kWh})$ is $1.6 \%$ below the HOMER PV output $(14,273 \mathrm{kWh})$. A smaller measured amount can be explained in part by an unusual number of days with snow cover on the PV array in Dec - Mar. This agreement demonstrates that, on average, the HOMER estimates are reasonable.

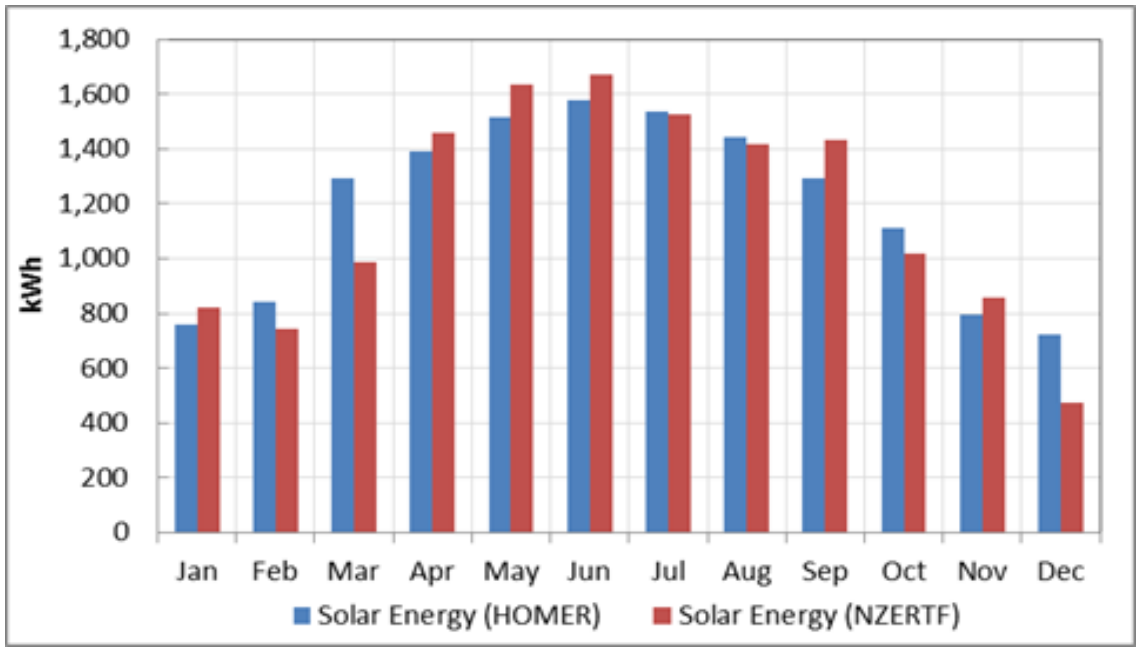

Figure 8. Comparison of HOMER solar energy estimates to measured NZERTF meter data for period of July 2013 - June 2014 (data is transposed starting with Jan 2014, then Jul 2013).

\footnotetext{
${ }^{[1]}$ During the first testing year (Jul. 2013- Jun. 2014), the NZERTF data set contained only 359 days of solar output. It does not include data from Aug. $2^{\text {nd }}$ to Aug. $6^{\text {th }}$, and Dec. $26^{\text {th }}$ due to instrumentation issues. Therefore, NZERTF totaled annual solar production is scaled to 365 days by adding the average apportioned monthly output.
} 


\subsection{Tariffs}

In order to determine how different tariff structures impact DER economics, simulations were conducted using four tariffs representing three major types of tariff structures. The tariffs below are also shown graphically in Figure 1.

- Flat Rate - D.C. Potomac Electric Power Company (Pepco) residential tariff;

- Time-of-Use (TOU) Tariff - New York Consolidated Edison (ConEd) tariff and Oklahoma Gas and Electric (OG+E) tariff; and

- Real-time Pricing Tariff - Chicago Commonwealth Edison (ComEd) Residential Realtime Pricing (RRTP) tariff, based on PJM hourly market clearing price.

\subsubsection{Flat Rate Tariff}

A flat rate tariff is one where the electricity price does not change over time. This is the most commonly used residential tariff today. The flat rate tariff used in this study is based on the D.C. Pepco flat rate, which was $\$ 0.11 / \mathrm{kWh}$ in 2014 . The flat rate tariff model includes generation, transmission, and distribution costs, but excludes taxes and fees.

\subsubsection{Time-of-Use Tariff}

Time-of-use (TOU) tariffs are characterized by having different rates during specified blocks of time. Higher rates apply during time blocks where higher demand is expected and lower rates apply during time blocks where lower demand is expected. For example, there might be one rate for Monday - Friday daytime and a lower rate for evenings and weekends. There may also be seasonal variations in time blocks or rates.

In this report, two TOU tariffs are used for the economic value analysis: New York Consolidated Edison (ConEd) residential TOU tariff, and Oklahoma Gas \& Electric (OG+E) TOU tariff. The ConEd tariff has extreme rates compared to other U.S. utilities due to transmission constraints around New York City. The OG+E tariff has more moderate price differentials. Table 1 shows the ConEd TOU rates for residential customers in New York City with less than $10 \mathrm{~kW}$ peak demand [9]. Table 2 shows the OG+E TOU residential tariff [10]. Both TOU tariff models include generation, transmission, distribution cost, excluding taxes and fees.

Table 1. New York Consolidated Edison time-of-use rates for residential customers

\begin{tabular}{lcrl|rl|rl}
\hline \multicolumn{6}{c}{ ConEd SC1-Residential Rate II - Voluntary Time-of-Day (basic service charge excluded) } \\
\hline & \multicolumn{2}{c}{ Total } & \multicolumn{2}{c}{ Supply Charge } & Energy Delivery Charge \\
\hline Jun-Sep & Mon-Fri 10am-10pm & 48.78 & $\phi / \mathrm{kWh}$ & 18.03 & $\phi / \mathrm{kWh}$ & 30.75 & $\phi / \mathrm{kWh}$ \\
& All other hours & 5.25 & $\phi / \mathrm{kWh}$ & 4.07 & $\phi / \mathrm{kWh}$ & 1.18 & $\phi / \mathrm{kWh}$ \\
Other & Mon-Fri 10am-10pm & 23.84 & $\phi / \mathrm{kWh}$ & 12.69 & $\phi / \mathrm{kWh}$ & 11.15 & $\phi / \mathrm{kWh}$ \\
months & All other hours & 5.46 & $\phi / \mathrm{kWh}$ & 4.28 & $\phi / \mathrm{kWh}$ & 1.18 & $\phi / \mathrm{kWh}$ \\
\hline
\end{tabular}


Table 2 Oklahoma Gas \& Electric time-of-use rates for residential customers

\begin{tabular}{lcrc}
\hline \multicolumn{2}{l}{ R-TOU - Residential TOU (basic service charge excluded) } \\
\hline \multicolumn{3}{c}{ Energy Charge } \\
\hline Jun-Sep & Mon-Fri 2pm-7pm & 14.00 & $\phi / \mathrm{kWh}$ \\
& All other hours & 2.70 & $\phi / \mathrm{kWh}$ \\
Other months & All other hours & 5.73 & $\phi / \mathrm{kWh}$ \\
\hline
\end{tabular}

\subsubsection{Real-Time Pricing Tariff}

A real-time pricing tariff is characterized by a continuously varying price that reflects the cost of generation at that time. In this study a Chicago Commonwealth Edison (ComEd) Residential Real Time Pricing (RRTP) Tariff was used [11]. The ComEd RRTP tariff has hourly prices that are derived from PJM wholesale spot market prices. RRTP pricing data were collected during the period from July 2013 - July 2014. Normally RRTP unit pricing remains below the flat rate price. However, during the summer season, RRTP price may rise as high as several dollars per kWh during extreme peaks. Figure 9 illustrates RRTP price for selected days in January 2014 and July 2013. Prices in January are around $0.10 \$ / \mathrm{kWh}$. Peak prices in July can be nearly 2.00 $\$ / \mathrm{kWh}$ [12]. The RRTP tariff model includes generation, transmission and distribution costs, excluding taxes and fees.
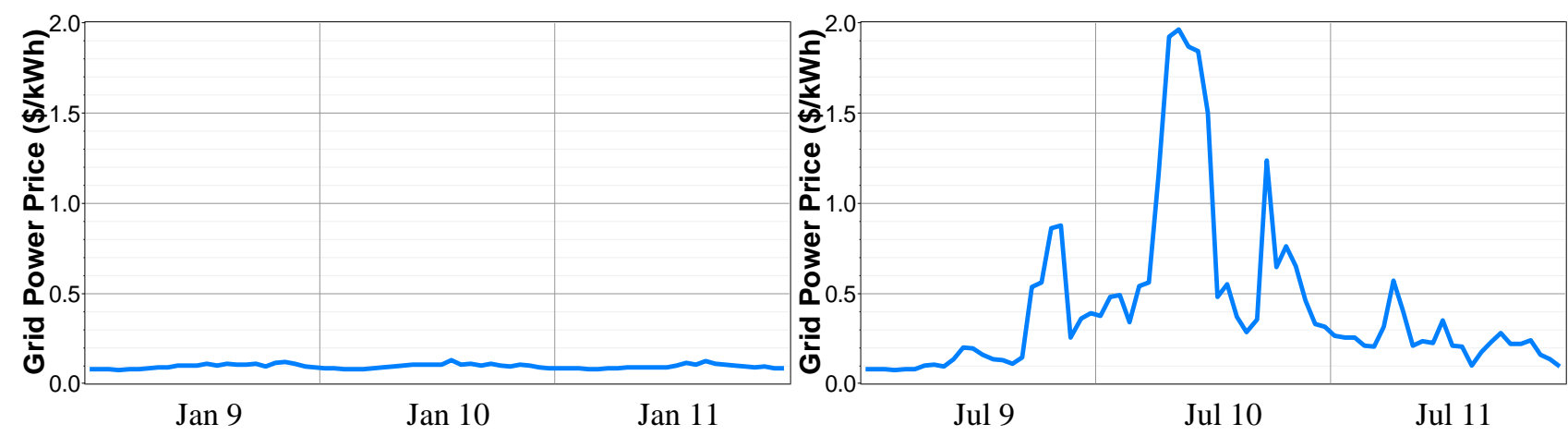

Figure 9. Historical ComEd real-time pricing for residential customers.

\subsection{Purchase/Sellback Price}

The relationship between purchase price and sellback price varies by location. For some utilities the sellback price is lower, accounting for costs that are not related to generation expenses. An example of this is the Pepco service area where the sellback price varies seasonally but overall is about $70 \%$ of the total purchase price [13]. In some places policies are established to encourage $\mathrm{PV}$ generation and there is a sellback premium. Minnesota is an example where a determination of the "value of solar" results in a sellback price that is $120 \%$ of the purchase price [14]. In other places the sellback price is the same as the purchase price. For the analysis in this report, sellback prices of $70 \%, 100 \%$, and $120 \%$ of the purchase price were considered. 


\subsection{Demand Charge}

Utilities must provision the grid infrastructure (e.g., transmission lines, substations, transformers, and peaking generators) to meet demand at all times. Utilities may place a demand charge in the customer tariff to cover the cost, where the customer is charged per $\mathrm{kW}$ for the highest demand recorded in a sliding 15, 30 or 60 minute window each month. A demand charge motivates customers to take action in order to reduce their peak demand; there is also some potential reduction in the utility's cost [15]. There may also be a penalty for exceeding some agreed upon limit. The demand charge may vary at different times of the day. The equation below shows how demand charge cost is calculated in HOMER, where $C_{\text {grid,demand }}$ is the total cost of the demand charge [5].

$$
C_{\text {grid,demand }}=\sum_{i}^{\text {rates }} \sum_{j}^{12} P_{\text {grid,peak }, i, j} \cdot c_{\text {demand }, i}
$$

where,

$$
\begin{aligned}
& P_{\text {grid,peak }, i, j}=\text { peak hourly grid demand in month } j \text { during the time that rate } i \text { applies }[k W] \\
& c_{\text {demand, } i}=\text { grid demand charge for rate } i[\$ / k W / \text { month }]
\end{aligned}
$$

For most residential customers today, there is no separate demand charge included on their monthly bills. For ComEd RRTP customers, demand charges are separated from their electricity supply charges. Demand charges are calculated based on capacity obligation and capacity charge rate (Equation 3). Capacity obligation represents a customer's expected level of hourly usage in the afternoon on a hot summer day (based on previous year's data). Capacity charge rate is updated annually based on the cost of capacity in the PJM wholesale market price [11].

$$
\text { Demand Charge }(\$)=\text { Capacity Obligation }(k W h) \times \text { Capacity Charge Rate }(\$ / k W h)
$$

Demand charges could impact the economic value results significantly. This report applies the Chicago ComEd demand charge and NY ConEd demand charge on top of the RRTP tariff (without demand charge) as a reference. The Chicago ComEd demand charge is constant at all times throughout the year (July 2013- Jun 2014) at 22.00 \$/kW/month. The NY ConEd demand charge rate follows the TOU schedule with a rate of $17.98 \$ / \mathrm{kW} / \mathrm{month}$ on peak (10a.m.-10p.m., Mon.-Fri.) and $4.38 \$ / \mathrm{kW} / \mathrm{month}$ off peak (all other hours). This is in addition to the supply and energy charges shown in Table 1.

\subsection{Energy Storage Model}

\subsubsection{Optimum Sizing of energy storage}

Energy storage can be a valuable resource for residential customers to shed load as well as store solar energy. Optimal sizing of energy storage, in order to minimize the COE, depends on many factors such as purchase/sellback price, demand charges, size of the PV array, size of the inverters, setpoint state of charge, and dispatching strategies. 
There are many types of commercially available electrical storage systems that could potentially be applied in residential applications. An economic analysis conducted in 2012 [16] concluded that most types of electrical storage were not yet cost-effective. To investigate the impact of energy tariffs on the economics of energy storage, a commercially available battery technology not available in 2012 was selected as an example storage system. This battery has the following characteristics:

- cycle life (defined as retained capacity $=80 \%$ initial capacity) of more than 3000 cycles,

- $100 \%$ initial depth of discharge;

- nominal DC voltage $48 \mathrm{~V}$ and 51 Ah capacity at 20 hour discharge (one battery unit has nominal $2.45 \mathrm{kWh}$ capacity);

- 15 A maximum charging current; and

- Cost: $\$ 1,115$ per unit for installation, $\$ 200$ per unit for replacement, no O\&M cost.

\subsubsection{Dispatch Strategy}

HOMER supports two dispatch strategies for battery storage, "load following" and "cycle charging" [5], with cycle charging chosen for this research. In the cycle charging strategy, batteries are charged by both the grid's power and PV solar production. PV power is applied first to serve house load. If excess PV power is available it is either used to charge the batteries or sold to the grid depending on the grid sellback price at the time. If the battery charge is below its setpoint state of charge, $\mathrm{PV}$ power is not available, and the grid purchase price is less than the battery energy cost plus battery wear cost, then the battery will charge from the grid until it reaches the setpoint state of charge. If the battery is above its minimum allowable state of charge, the grid purchase price is higher than the battery energy cost plus battery wear cost, and PV power cannot meet the load, then the battery will discharge. For the simulations conducted, the following dispatch parameters were used:

- battery minimum allowable state of charge $20 \%$

- battery setpoint state of charge $80 \%$

\section{SIMULATION RESULTS}

\subsection{Sizing of Energy Storage}

The value of batteries and optimal number of batteries is shown to increase with both the average price of electricity, as well as the magnitude of price variation present in tariffs. In this section, different sizes of the energy storage units (batteries) are analyzed along with COE for different tariffs. Figure 10 shows COE for PV systems with various battery capacities for different tariffs. Similar patterns are seen for flat rate, OK TOU, and RRTP tariffs where COE increases with battery size. Although increasing the battery size does not reduce COE for these tariffs, the patterns get steeper starting at $9.8 \mathrm{kWh}$ battery size. The $9.8 \mathrm{kWh}$ battery size is used for energy storage analysis in Sections 3.2 to 3.5. 


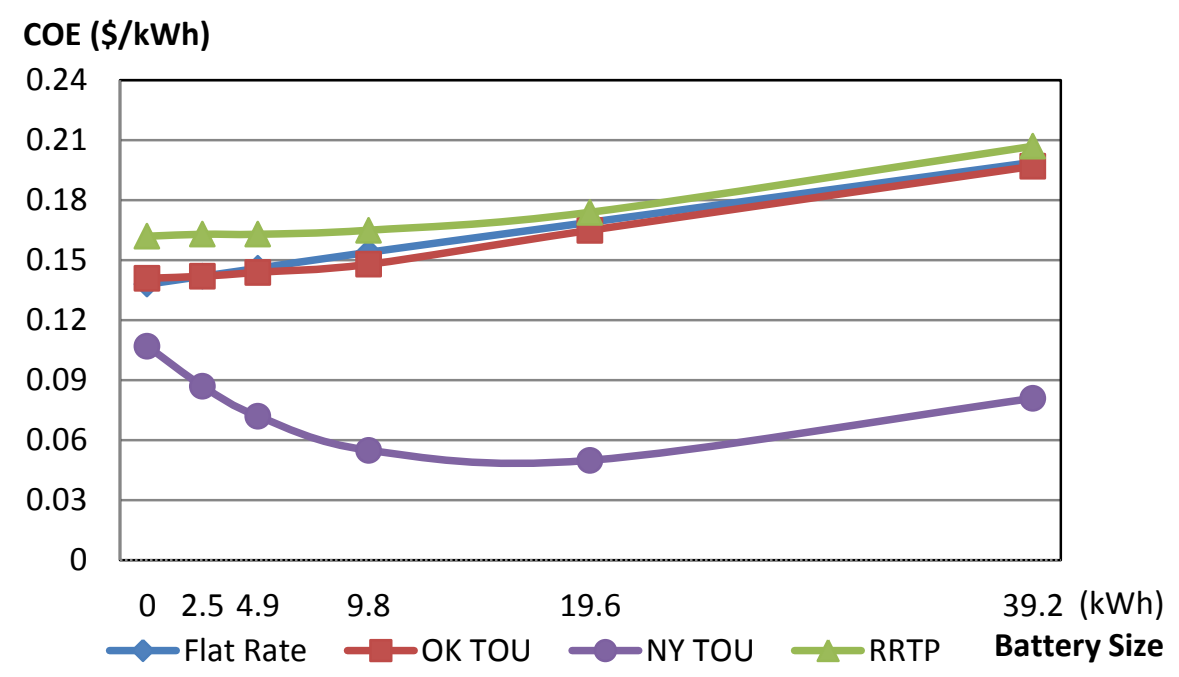

Figure 10. Cost of energy based on different sized energy storage under different tariffs.

The cost of storage for the NY TOU tariff shows a different pattern. Due to the high NY TOU electricity rate, COE drops down as batteries are added up to a size of $19.6 \mathrm{kWh}$ ( 8 batteries, about half of the average daily consumption), but then increases for the $39.2 \mathrm{kWh}$ size. The 19.6 $\mathrm{kWh}$ energy storage delivers a COE of $0.05 \$ / \mathrm{kWh}$. This shows that batteries can increase grid reliability under the NY TOU tariff while also reducing costs to the homeowner. For the other tariffs, use of batteries provides no benefit to the homeowner for arbitrage purposes.
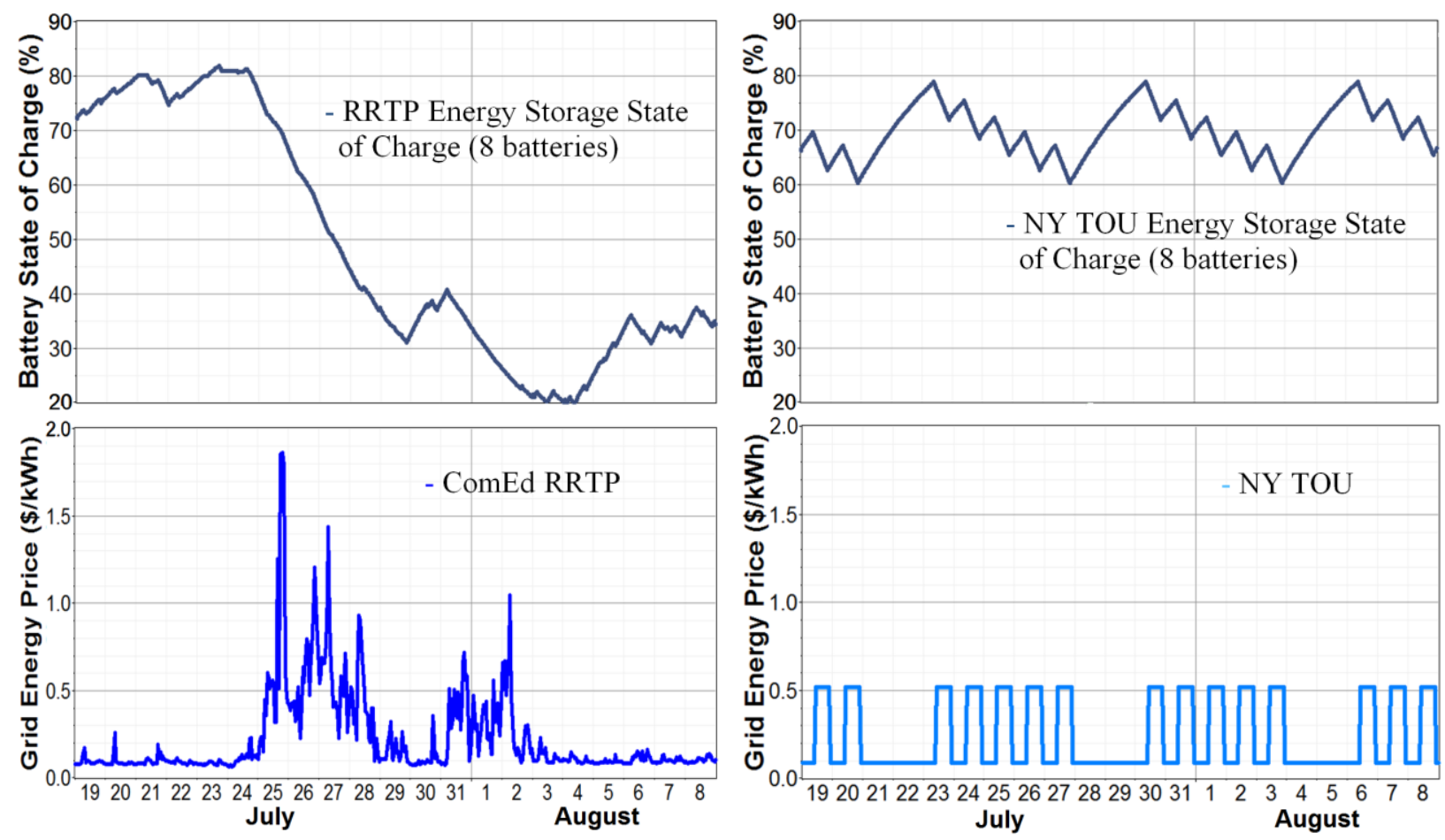

Figure 11. Impacts of RRTP and NY TOU energy rates to energy storage (batteries) state of charge. 
Figure 11 shows the charging and discharging pattern for the $19.6 \mathrm{kWh}$ battery option for the July and August summer period, demonstrating battery charging strategy performance for the ComEd RRTP and NY TOU rates. The battery system is fully depleted across the high price RRTP peaks in July and early August, while the TOU rate results in regular charge/discharge cycles.

\subsection{Effects of Dynamic Tariffs}

Figure 12 shows the impacts of the selected tariffs on COE for various combinations of DER. Because the four tariffs come from different states, the baseline COE with No DER ranges from $0.058 \$ / \mathrm{kWh}(\mathrm{OK})$ to $0.178 \$ / \mathrm{kWh}(\mathrm{NY})$. For this reason, it is the trend of each curve that is of interest, not the absolute magnitude.

The Pepco Flat Rate COE starts from $0.116 \$ / \mathrm{kWh}$ for no DER and rises to $0.154 \$ / \mathrm{kWh}$ after PV array and energy storage are both applied to the system. The OK TOU COE jumps significantly when DER is applied to the system because of the capital cost of the PV array and the low base price for electricity. The Chicago RRTP COE increases from 0.131 \$ $/ \mathrm{kWh}$ to 0.150 $\$ / \mathrm{kWh}$ by adding DER. However, the NY TOU tariff leads to a strong benefit from the DER. COE drops from $0.178 \$ / \mathrm{kWh}$ to $0.055 \$ / \mathrm{kWh}$ with the combination of PV array and energy storage.

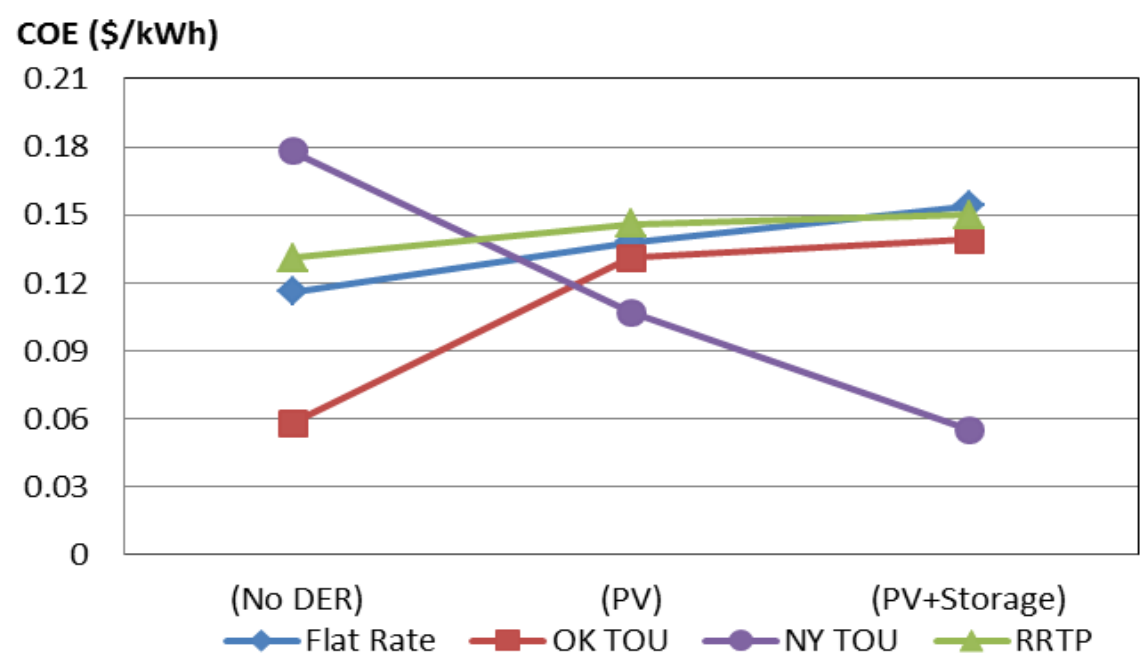

Figure 12. Cost of energy with various combinations of DER for selected tariffs.

These results show that the base price of electricity significantly impacts the economic viability of a PV system with or without storage. Only in the case of a high base price and extreme price fluctuations is the PV system economically viable. These results do not take into consideration renewable energy tax credits, which can have a significant impact and vary widely between locations. Section 3.6 will discuss the impact of tax credits, using Maryland renewable tax credits as an example. 


\subsection{Renewable Fraction}

The renewable fraction, defined as the fraction of energy delivered to the load that is sourced from the rooftop PV, is shown in Figure 13 for each tariff. Although the NZERTF solar PV system produced slightly more power in the test year than was consumed by loads in the house, the amount of load served directly by power from the PV array was only $58 \%$. The remaining $42 \%$ of house power was sourced from the grid, while the excess power from the PV array when available was sold to the grid.

The figure also shows that the tariff has no impact on the renewable fraction for the PV only case, since the consumption data was taken as a constant input. If loads had been shifted in response to the different tariffs (as might be expected), then there would be some variation in the renewable fraction. Figure 13 also shows that the battery charging algorithm does respond to the different tariffs in such a way that there is variation in renewable fraction. It also shows that adding a battery system lowers renewable fraction when the battery is used for arbitrage.

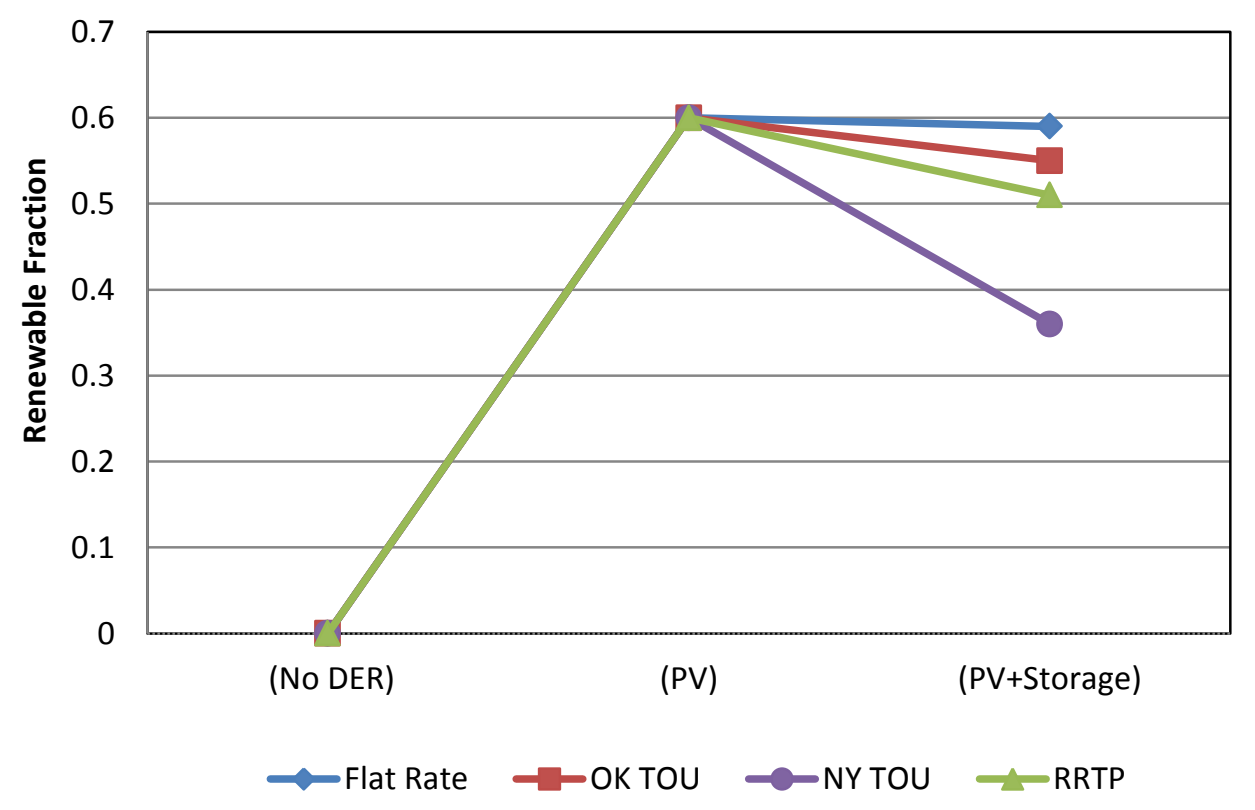

Figure 13. Fraction of energy served by renewable power sources. 


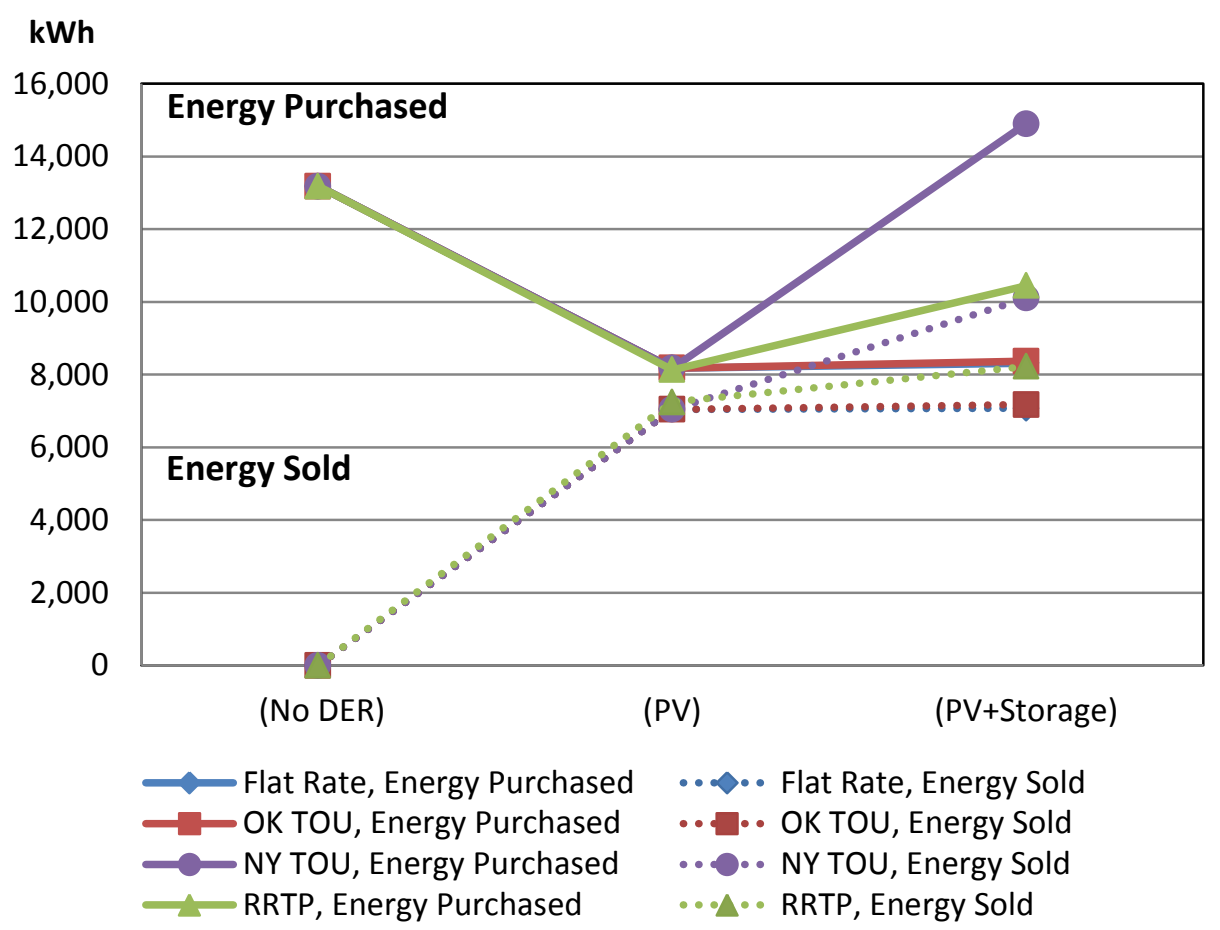

Figure 14. The amount of purchased electricity and sold for selected tariffs. The flat rate tariff data is covered by the red (OK TOU) lines.

Figure 14 shows the amount of electricity purchased and sold under the four tariffs. Since the NZERTF consumed 13,176 kWh during the test year, the "no DER" system purchased the same amount of energy for all tariffs. Adding PV reduces the energy purchased and increases the amount sold, with no difference among tariffs. Results diverge when adding storage, since the amount sold or purchased is influenced by the tariff. In general, adding a battery system increases energy transactions between the system and the grid.

\subsection{Effects of Electricity Sellback Price}

Figure 15 shows how different sellback prices affect the cost of energy for the ComEd RRTP tariff. Three different sellback prices are considered: $70 \%, 100 \%$, and $120 \%$ of the purchase price. Customers with DER systems will see the most benefit for selling excess power if they get the higher $(120 \%)$ sellback price. While the $120 \%$ price makes PV and storage more economical, the COE for PV + Storage with $120 \%$ sellback price $(0.139 \$ / \mathrm{kWh})$ is still higher than the base case with no DER $(0.131 \$ / \mathrm{kWh})$. As expected, COE is increased from 0.131 $\$ / \mathrm{kWh}$ (no DER) up to $0.176 \$ / \mathrm{kWh}(\mathrm{PV}+$ Storage) with the $70 \%$ sellback price. 


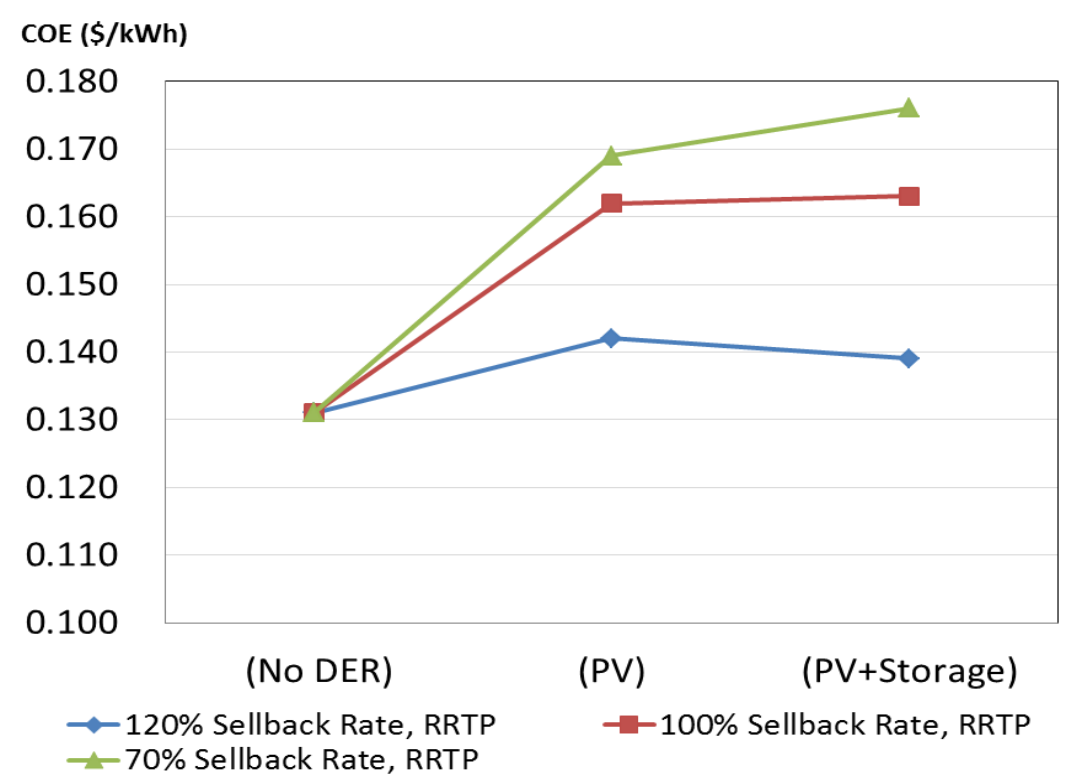

Figure 15. Impact of sellback price on COE.

\subsection{Effects of Demand Charge}

Figure 16 shows the cost of energy for two different demand charge rates applied to the system. Chicago ComEd demand charge rates (22.0 \$/kW/month) and NY Con Edison demand charge rates (17.98 \$/kW/month on peak and $4.38 \$ / \mathrm{kW} /$ month off peak) are applied on top of ComEd RRTP rates. The ComEd RRTP rate without demand charges is also shown for reference.

Figure 16 shows that the ComEd demand charge approach results in higher costs for no DER, but benefits when PV panels are added to generate power. All PV power is produced on peak, and thus is paid at a higher rate under the ComEd tariff resulting in the lower COE with DER.

Results show that demand charges do not impact the value of batteries. This result is likely due to a battery control algorithm that is not designed to flatten demand peaks. However, the demand charge in two existing tariffs represents half the monthly energy cost. Therefore, a battery with a charging algorithm designed to reduce house demand peaks could significantly reduce the monthly energy bill. However, this goal may conflict to some degree with shifting energy use to off-peak periods. 


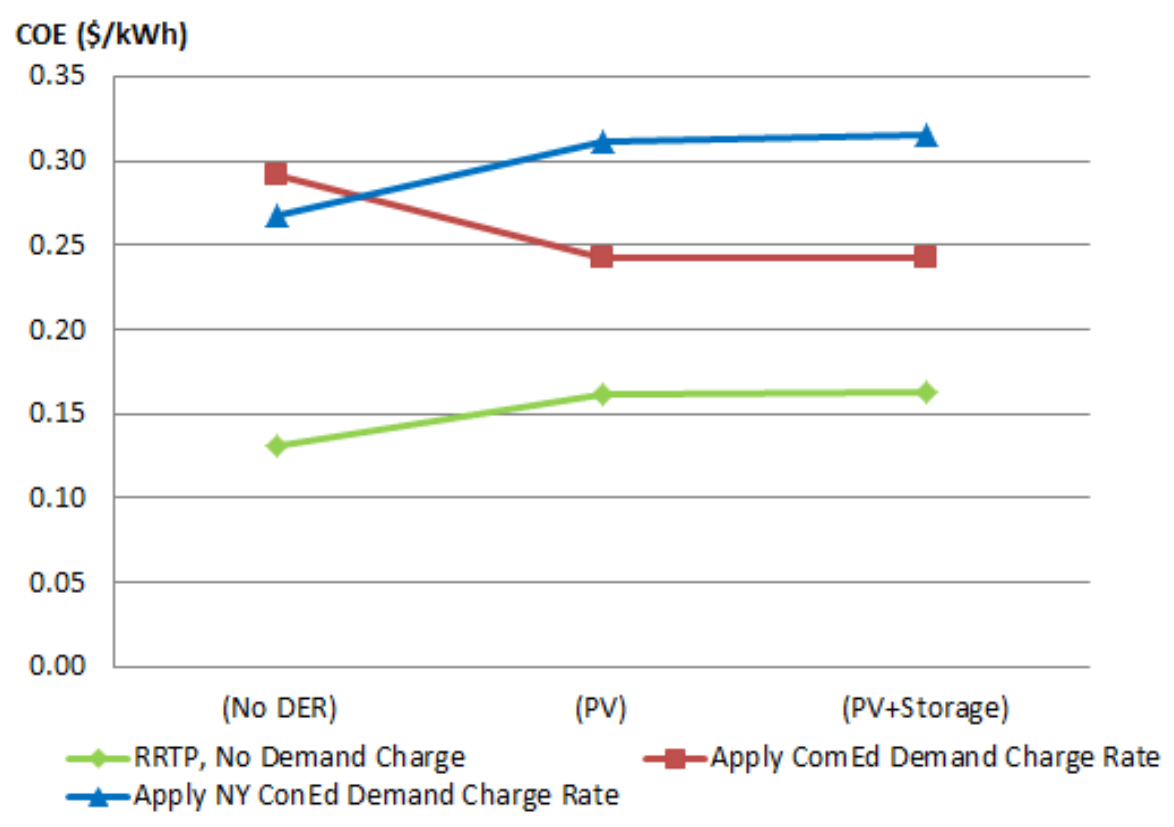

Figure 16. Impacts of demand charge on COE for the RRTP tariff.

\subsection{Impacts of tax credits on COE in Maryland}

Maryland has a variety of incentives that encourage investment in renewable and energy efficient technologies. Table 3 summarizes monetary incentives that apply to residential solar PV systems.

Table 3 Maryland financial incentives for residential solar systems

\begin{tabular}{|l|l|}
\hline \multicolumn{1}{|c|}{ Financial incentive/payment } & \multicolumn{1}{c|}{ Value } \\
\hline \multicolumn{1}{|c|}{ Upfront MD state tax rebate } & \multicolumn{1}{c|}{$\$ 1000$} \\
\hline Federal tax credit & \multicolumn{1}{c|}{$30 \%$ of system cost } \\
\hline $\begin{array}{l}\text { State Renewable Energy Credits (SREC). SRECs are } \\
\text { tradable credits that represent the clean energy benefits of } \\
\text { electricity generated from a solar energy system. When a } \\
\text { solar system generates 1 MWh of electricity, an SREC is } \\
\text { issued which can then be sold or traded separately from the } \\
\text { power. }\end{array}$ & $\begin{array}{l}\text { In the last several years, the MD market } \\
\text { value of SRECs has stayed at } \\
\text { approximately \$150/MWh. The house } \\
\text { PV system produced 13.7 MWh in the } \\
\text { demo year, valued at approximately } \\
\$ 2000 .\end{array}$ \\
\hline
\end{tabular}

Tax credits and financial incentives were not included in the analysis up to this point. However, the tax credits and incentives could have significant $\mathrm{COE}$ impact on a homeowners purchase decision. The homeowner receives the PV energy and any sellback credits for energy provided to the grid. In Maryland, the incentives and tax credits are provided upfront to the homeowner who purchases a solar system. To illustrate the impact of the Maryland incentives, the initial credits 
were applied to the system cost and a yearly payment of $\$ 2,000\left(\mathrm{SRECs}^{1}\right)$ was assumed. Figure 17 shows the revised COE when including these Maryland incentives. Results show that the cost of PV is significantly reduced when these tax rebates/credits and SRECs are included.

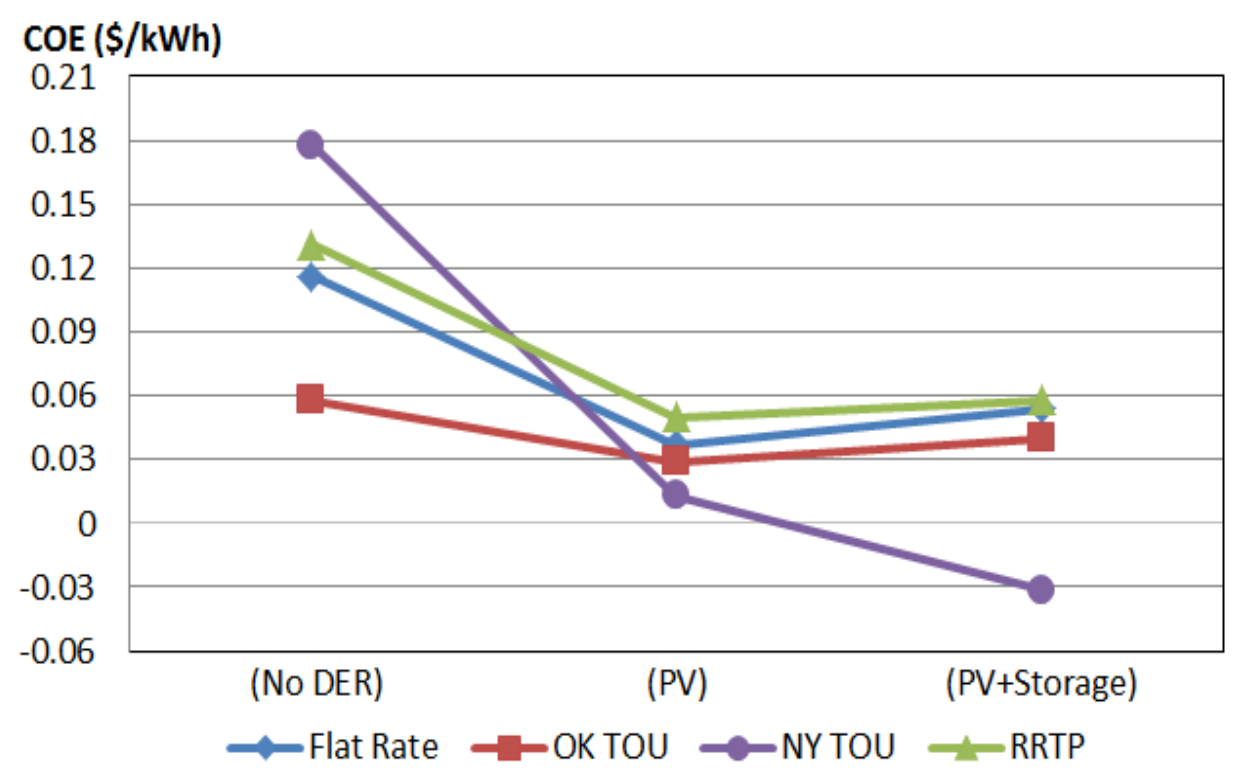

Figure 17. Cost of energy including Table 3 renewable rebates and credits.

Comparing Figure 17 with Figure 12, it is clear that addition of a PV system is economically viable for any of the four tariffs, with $\mathrm{COE} \leq 0.05 \$ / \mathrm{kWh}$, including for the existing Maryland flat rate tariff. The addition of storage does not lower the cost unless there are significant price differentials. However, a homeowner may want to purchase a battery system for backup power.

\section{CONCLUSION}

The impact of four different electricity tariffs on the economics of customer distributed energy resources was evaluated for the NIST Net-Zero Energy Residential Test Facility (NZERTF). The analysis was conducted using Hybrid Optimization Model for Electric Renewables (HOMER) simulations that were validated using performance data from the NZERTF. The tariffs investigated represent published information for tariffs in use in various locations in the United States. A flat-rate tariff from the D.C. Potomac Electric Power Company (the electricity provider for the NZERTF) was used as a base case. The other tariffs were a time-of-use (TOU) tariff from Oklahoma Gas and Electric, a TOU tariff from New York Consolidated Edison (ConEd), and a real-time pricing tariff from Chicago Commonwealth Edison (ComEd).

The total cost of energy (COE) was used as the economic performance metric. This includes the cost of electricity purchased, credit for energy sold, capital equipment costs, and operation and

\footnotetext{
${ }^{1}$ In reality, the SREC market value will likely fluctuate, and may change considerably, over the life of the system. This is therefore only a rough estimate of SREC value.
} 
maintenance cost. For each tariff, three cases were considered: no DER, PV generation, and PV generation with battery storage. The impact of renewable energy incentives based on current policies in the state of Maryland was also presented. The energy consumption pattern was constant for all the simulations; there was no attempt to shift or reduce loads based on price of electricity.

The results show that for three of the four tariffs the use of customer DER without incentives increased COE. The exception was for the New York TOU tariff. In this case the significant difference between peak and off-peak prices made both PV and battery storage economically viable. Applying Maryland renewable energy incentives made the PV array economically viable for all tariffs.

Results show that the COE initially increases slightly for three of the tariffs as battery storage is added and eventually rises more steeply. For the ConEd TOU tariff, adding storage is initially beneficial and then begins to increase COE. Applying the Maryland incentives did not significantly affect this pattern, but did reduce COE significantly. For the ConEd TOU tariff, the addition of PV plus batteries lowered the COE from $0.18 \$ / \mathrm{kWh}$ to $0.05 \$ / \mathrm{kWh}$ over the life of the PV + battery system (before applying incentives). In this study the benefit of standby power during an outage was not considered.

The COE is reduced in all cases with DER for all tariffs when the sellback rate is higher. Lower sellback rates make selling PV power to the grid less profitable and make it more profitable to store excess PV generation for use during peaks. However, the DER system may not be economically justified for lower sellback rates.

The impact of demand charges was investigated and the results showed no impact on the value of batteries. This may be a result of the HOMER battery control algorithm, which was not designed to flatten demand peaks. The demand charges in two existing residential tariffs (ComEd and ConEd) represent approximately half the monthly electric bill cost. Therefore, a battery charging algorithm designed to reduce demand peaks could potentially reduce the monthly energy bill significantly.

While the NZERTF solar PV system produced slightly more power in the test year than was consumed by loads in the house, the amount of power from the PV system that was actually consumed directly by loads in the house (the local renewable energy fraction) was only $58 \%$. The remaining power from the PV panels was sold to the grid. Adding battery storage reduced the renewable energy fraction because power from batteries was sometimes sold to the grid during high price periods.

\section{REFERENCES}

[1] NETL, "430.01.03 Electric Power System Asset Optimization," DOE/NETL-430/061110, Mar 7, 2011. 
[2] EIA, “Today In Energy” Feb 18, 2014.

http://www.eia.gov/todayinenergy/detail.cfm?id=15051\#tabs_SpotPriceSlider-7 (retrieved May 30, 2015).

[3] Faruqui, A., "Dynamic Pricing 2.0: The Grid-Integration of Renewables," IEEE PES GM 2013 Meetings, Vancouver, July 23, 2013.

[4] Kneifel, J., "Energy Performance of the NIST Net Zero Energy Residential Test Facility relative to a Maryland Code-Compliant Design," NIST Special Publication 1166, Sep 2013, http://dx.doi.org/10.6028/NIST.

[5] Lambert, T., Gilman P., Lilienthal P., "Micropower System Modeling with HOMER," National Renewable Energy Laboratory, 2008.

[6] Omar, F., Bushby, S.T., "Simulating Occupancy in the NIST Net-Zero Energy Residential Test Facility," NIST TN 1817, 2013.

[7] Fanney, A.H., et.al., "Net-zero and beyond! Design and performance of NIST's net-zero energy residential test facility," Energy and Buildings 101 (2015) 95-109.

[8] NASA Langley Research Center Atmospheric Science Data Center Surface Meteorological and Solar Energy (SSE) web portal, https://eosweb.larc.nasa.gov/cgi-

bin/sse/sse.cgi?skip@larc.nasa.gov+s03\#s03 (retrieved Sep 2014).

[9] Consolidated Edison Company, New York, "Electric Rates and Tariffs," http://www.coned.com/documents/elecPSC10/SCs.pdf (retrieved Sep 2014).

[10] Oklahoma Gas and Electric, "Oklahoma Rate Tariffs - Residential Time of Use," https://oge.com (retrieved Sep 2014).

[11] Chicago Commenwealth Edison, "The ComEd Residential Real Time Pricing Program, Guide to Real-Time Pricing." June 2014. https://rrtp.comed.com/wpcontent/uploads/2014/09/RRTPGuide2014-06-final.pdf (retrieved Oct 2014).

[12] PJM Energy Market website, http://www.pjm.com/markets-and-operations/energy.aspx (retrieved 2014).

[13] PEPCO, “PEPCO Residential Rate Schedule-R,” http://www.pepco.com/rateschedules.aspx (retrieved Oct 2014).

[14] Farrell J., "Minnesota's Value of Solar: Can a Northern State's New Solar Policy Defuse Distributed Generation Battles?” Institute for Local Self-Reliance, April 2014.

[15] Schweppe, F. C., "Spot Pricing of Electricity," Boston: Kluwer Academic Publisher, 1988.

[16] Zheng, M., Meinrenken C., and Lackner K., "Electricity Storage in Buildings for Residential Sector Demand Response: Control Algorithms and Economic Viability Evaluation," NIST GCR, 2012. 